Gut, 1973, 14, 716-722

\title{
Fatty acid composition of plasma lipoproteins in control subjects and in patients with malabsorption
}

\author{
T. SHIMOYAMA ${ }^{1}$, H. KIKUCHI ${ }^{2}$, M. PRESS, AND G. R. THOMPSON
}

From the Department of Medicine, Royal Postgraduate Medical School, Hammersmith Hospital, London

SUMMARY The fatty acid composition of cholesterol (cholesteryl) ester, triglyceride, and lecithin has been investigated in whole plasma and individual lipoproteins of healthy control subjects, of patients with malabsorption, and also of patients without malabsorption. The results show a decreased proportion of the essential fatty acid linoleic acid in all three lipid classes in both groups of patients as compared with the healthy controls. This abnormality was more marked in the malabsorbers, especially those with steatorrhoea secondary to intestinal resection. Unequivocal biochemical evidence of essential fatty acid deficiency, as indicated by the appearance of 5,8,11 eicosatrienoic acid in plasma lecithin, was observed in two patients, both of whom had undergone major intestinal resections. The results suggest that intestinal resection predisposes to the development of essential fatty acid deficiency.

The literature on the biochemistry and physiology of essential fatty acids and the syndrome of essential fatty acid deficiency in experimental animals is extensive and has been reviewed relatively recently (Alfin-Slater and Aftergood, 1968). Yet little is known about the occurrence of essential fatty acid deficiency in man, apart from the investigation carried out by Hansen, Wiese, Boelsche, Haggard, Adam, and Davis (1963) who described dermal changes, retardation of growth, and increased caloric requirements in previously healthy infants fed diets low in linoleic acid. Although decreased plasma essential fatty acid levels were reported in children with steatorrhoea due to cystic fibrosis of the pancreas (Kuo and Huang, 1965; Caren and Corbo, 1966) and coeliac disease (Rey, Frézal, Polonovski, and Lamy, 1965), it is only recently that both biochemical and clinical signs of actual deficiency have been demonstrated in an adult patient with malabsorption (Collins, Sinclair, Royle, Coats, Maynard, and Leonard, 1971).

The relative paucity of information on essential fatty acid deficiency in adults and the likelihood that patients with steatorrhoea are especially at risk prompted the present study. The fatty acid patterns of each of the major lipid classes have been

${ }^{1}$ Present address: Hyogo College of Medicine, Hyogo, Japan

'Present address: Hirosaki University School of Medicine, Hirosaki, Japan

Received for publication 20 June 1973. investigated in whole plasma from patients with various forms of malabsorption and compared with healthy and 'sick' controls. Because of discrepancies in the literature as to the extent to which each of the different species of plasma lipoproteins vary in their fatty acid composition (Lindgren and Nichols, 1961); Nichols, Rehnborg, Lindgren, and Wills, 1962; Kayden, Karmen, and Dumont, 1963; Goodman and Shiratori, 1964), these have also been compared in control subjects and some of the malabsorbers.

\section{Methods}

SUBJECTS

Blood was obtained after an overnight fast (10-14 hours) from seven male and seven female healthy control subjects, whose ages ranged from 20 to 40; five 'sick' controls, aged 22 to 82 , ie, patients admitted to hospital two to six weeks previously with illnesses unassociated with malabsorption, four of them males, with diagnoses of chronic bronchitis, pneumonia, carcinoma of the colon, and septicaemia respectively, and a female with colonic diverticulosis; and 24 patients with intestinal malabsorption, the latter being due to intestinal resection in six patients (three of whom were male), adult coeliac disease in 12 nine of whom were female), and to other causes in six (five of them male), including three patients with pancreatic dysfunction. Clinical details of these patients are shown in table I. The mean daily faecal 
fat excretion in the three subgroups of malabsorbers was $17 \mathrm{~g}, 18 \mathrm{~g}$, and $25 \mathrm{~g}$ respectively. Three of the patients with adult coeliac disease were on a glutenfree diet but all the other patients studied were on a normal ward diet, containing approximately $70 \mathrm{~g}$ fat (the fatty acid composition of this diet was not analysed but is known to have a low content of polyunsaturated fats). One of the resection patients had intermittently received supplements of medium chain triglycerides in the past (patient no. 6, table I). The healthy control subjects consumed individual diets that differed from the ward diet.

\section{SEPARATION OF LIPOPROTEINS}

Blood samples were mixed with EDTA ( $2 \mathrm{mg}$ per $\mathrm{ml}$ ) and the plasma was separated. Preparative ultracentrifugation was carried out as described by Havel, Eder, and Bragdon (1955) but using an MSE Superspeed 40 ultracentrifuge with a $3 \times 20 \mathrm{ml}$ swing-out rotor. Samples of plasma $(4 \mathrm{ml})$ were centrifuged successively at d 1.006 and 1.063 at $15-16^{\circ}$ for 16 hours at $30000 \mathrm{rpm}(100000 \times \mathrm{g})$. The supernatants from the first and second spins were aspirated and contained very low density lipoprotein (VLDL) and low density lipoprotein (LDL) respectively, whereas high density lipoprotein (HDL) was obtained in the infranatant of the second spin. Preparative ultracentrifugation was usually commen- ced within 12 hours of the taking of blood samples, the plasma being kept at $4^{\circ}$ in the meantime.

\section{SEPARATION OF LIPIDS}

Lipids were extracted from whole plasma or lipoprotein fractions into chloroform:methanol (2:1, $\mathrm{v} / \mathrm{v}$ ) as described by Folch, Lees, and Sloane Stanley (1957). The phases were separated by the addition of $0.7 \% \mathrm{KCl}$ in $0.02 \mathrm{~N} \mathrm{HCl}$ followed by centrifugation. The chloroform phase was then dried in a rotary evaporator under nitrogen and the lipids were redissolved in $0.5 \mathrm{ml}$ redistilled hexane and separated by thin-layer chromatography on silica gel $G$ plates $(0.25 \mathrm{~mm}$ thickness). Triglycerides and cholesterol esters were separated in the solvent system petroleum ether:di-ethyl ether:glacial acetic acid $(82: 17: 1, \mathrm{v} / \mathrm{v})$ whereas lecithin was isolated on a separate plate, using chloroform:methanol:glacial acetic acid:water $(65: 25: 8: 4, \mathrm{v} / \mathrm{v})$. The lipids were visualized under ultraviolet light after spraying the dried plates with $0.02 \% 4,5$-dichlorofluorescein in ethanol $(w / v)$ and then scraped off into test tubes. Triglycerides and cholesterol esters were separately extracted from silicic acid into $7 \mathrm{ml}$ hexane:di-ethyl ether $(85: 15, \mathrm{v} / \mathrm{v})$ whereas lecithin was extracted into $7 \mathrm{ml}$ chloroform:methanol:water:glacial acetic acid (50:38:8:4). Following the addition of $2 \mathrm{ml}$ $4 \mathrm{M} \mathrm{NH}_{4} \mathrm{OH}$, the coloured aqueous phase was re-

\begin{tabular}{|c|c|c|c|c|}
\hline Patient No. & Age (yr) & $\operatorname{Sex}$ & Diagnosis & Faecal Fat (g/day) \\
\hline 1 & 81 & $\mathbf{M}$ & $\begin{array}{l}\text { Intestinal resection } 7 \text { years previously } \\
\text { Remnant }=14 \text { inches jejunum }\end{array}$ & 28 \\
\hline 2 & 44 & $\mathbf{M}$ & $\begin{array}{l}\text { Intestinal resection } 3 \text { years previously } \\
\text { Remnant }=2 \text { inches jejunum }+2 \text { inches ileum }\end{array}$ & 31 \\
\hline 3 & 44 & $\mathbf{M}$ & $\begin{array}{l}\text { Intestinal resection } 16 \text { years previously } \\
\text { Remnant }=4 \text { feet jejunum }\end{array}$ & 4 \\
\hline 4 & 50 & $\mathbf{F}$ & $\begin{array}{l}\text { Intestinal resection } 2 \text { years previously } \\
\text { Remnant }=6 \text { inches jejunum }\end{array}$ & 36 \\
\hline 5 & 50 & $\mathbf{F}$ & $\begin{array}{l}\text { Intestinal resection } 2 \text { years previously } \\
\text { Remnant }=\text { all jejunum }+2 \text { inches ileum }\end{array}$ & 4 \\
\hline 6 & 63 & $\mathbf{F}$ & $\begin{array}{l}\text { Intestinal resection } 1 \text { year previously } \\
\text { Remnant }=4 \text { feet jejunum }\end{array}$ & 14 \\
\hline 7 & 34 & $\mathbf{M}$ & Adult coeliac disease & 6 \\
\hline $8^{1}$ & 50 & $\mathbf{M}$ & Adult coeliac disease & 20 \\
\hline 9 & 40 & $\mathbf{M}$ & Adult coeliac disease & 8 \\
\hline 10 & 24 & $\mathbf{F}$ & Adult coeliac disease & 8 \\
\hline $11^{1}$ & 61 & $\mathbf{F}$ & Adult coeliac disease & - \\
\hline 12 & 46 & $\mathbf{F}$ & Adult coeliac disease & 29 \\
\hline 13 & 50 & $\mathbf{F}$ & Adult coeliac disease & 18 \\
\hline 14 & 35 & $\mathbf{F}$ & Adult coeliac disease & - \\
\hline $15^{1}$ & 32 & $\mathbf{F}$ & Adult coeliac disease & 37 \\
\hline 16 & 57 & $\mathbf{F}$ & Adult coeliac disease & 25 \\
\hline 17 & 37 & $\mathbf{F}$ & Adult coeliac disease & 14 \\
\hline 18 & 59 & $\mathbf{F}$ & Adult coeliac disease & 11 \\
\hline 19 & 54 & $\mathbf{M}$ & Carcinoma of pancreas & 32 \\
\hline 20 & 72 & $\mathbf{M}$ & Chronic pancreatitis & 20 \\
\hline 21 & 23 & $\mathbf{M}$ & Intestinal lymphangiectasia & 5 \\
\hline 22 & 16 & $\mathbf{M}$ & Intestinal lymphangiectasia & 15 \\
\hline 23 & 41 & $\mathbf{M}$ & Blind loop & 40 \\
\hline 24 & 56 & $\mathbf{F}$ & Chronic pancreatitis & 37 \\
\hline
\end{tabular}

Table I Clinical details of patients with malabsorption

${ }^{1}$ On gluten-free diet 
moved and discarded. After adding $2 \mathrm{ml} \mathrm{50 \%}$ methanol the lower phase, in the case of lecithin, or the upper phase, in the case of cholesterol ester or triglyceride, was transferred to stoppered tubes and evaporated to dryness under nitrogen. Lipid recoveries from thin-layer plates averaged $82-94 \%$.

Saponification of lipids was carried out at $55-60^{\circ}$ for 20 minutes following the addition of $3 \mathrm{ml} 0.3 \mathrm{~N}$ methanolic KOH. After acidification with $0.6 \mathrm{~N}$ $\mathrm{H}_{2} \mathrm{SO}_{4}$ the fatty acids were extracted into hexane: diethyl ether $(80: 20 \mathrm{v} / \mathrm{v})$. Each extract was washed with water, then dried under nitrogen and methylated in stoppered tubes at $75^{\circ}$ for 90 minutes following the addition of $3 \mathrm{ml} 5 \% \mathrm{H}_{2} \mathrm{SO}_{4}$ in methanol (v/v). The methylated fatty acids were then extracted into redistilled hexane and stored at $-20^{\circ}$. Recovery of methylated fatty acids averaged $86-94 \%$.

GAS LIQUID CHROMATOGRAPHY PROCEDURES The methyl esters of the fatty acids of lecithin, triglyceride, and cholesterol ester were analysed in a Pye series 104 gas liquid chromatograph. The samples were applied to a glass column $(5 \mathrm{ft} \times 1 / 4 \mathrm{in}$.) packed with $20 \%$ diethylene glycol succinate on 100/120 mesh Diatomite C, at an oven temperature of $160^{\circ}$. The emergent peaks were identified by comparing their retention times with those of authentic standards and published data. A sample of $5,8,11$ eicosatrienoic acid for use as a standard was prepared from the plasma of male rats rendered deficient in essential fatty acids by keeping them on a fat-free diet for six weeks from the time of weaning. The peak constantly found in normal human plasma lecithin and having an $\mathrm{Rf}$ intermediate between that of 5,8,11 eicosatrienoic acid $(20: 3 \omega 6)$ and arachidonic acid was assumed to be $8,11,14$ eicosatrienoic acid $(20: 3 \omega 6)$ (Ullman and Sprecher, 1971).

The percentage distribution of the mass of fatty acids in each sample was calculated by multiplying peak height $\times$ retention time, which gave similar results to cutting out and weighing the individual peaks on photocopies of the original GLC trace. Statistical differences between groups were assessed by analysis of variance.

\section{Results}

\section{FATTY ACID COMPOSITION OF LIPIDS}

IN WHOLE PLASMA

The fatty acid composition of lipids in the plasma of healthy control subjects, 'sick' controls, and patients with malabsorption is shown in table II. The results reveal major differences in lecithin composition, both groups of patients having less linoleate (18:2) and more palmitate $(16: 0)$ and oleate $(18: 1)$ than healthy controls. The linoleate content of cholesterol ester was also reduced in both groups of patients, especially in the malabsorbers who showed a concomitant increase in palmitate, palmitoleate $(16: 1)$, stearate $(18: 0)$, and oleate. There were much less marked differences in triglyceride composition but again both groups of patients had less linoleate and more palmitoleate than controls, and in malabsorbers this was accompanied by an increase in myristate $(14: 0)$. There was no obvious correlation between the degree of steatorrhoea and percentage of linoleate in the plasma lecithin of malabsorbers.

\begin{tabular}{|c|c|c|c|c|c|c|c|c|c|}
\hline & $14: 0^{1}$ & $16: 0$ & $16: 1$ & $18: 0$ & 18:1 & $18: 2$ & $18: 3$ & $20: 3 \omega 6$ & $20: 4$ \\
\hline $\begin{array}{l}\text { Percentage Fatty Acids in } \\
\text { Controls }(n=14)^{2} \\
\text { Malabsorbers }(n=23) \\
\text { Patients }(n=5)\end{array}$ & $\begin{array}{l}\text { ecithin } \\
0.5 \pm 0.3 \\
1.1 \pm 0.7 \\
1.1 \pm 0.5\end{array}$ & $\begin{array}{l}26 \cdot 9 \pm 3 \cdot 0 \\
30 \cdot 1 \pm 3 \cdot 4 \\
33 \cdot 2 \pm 2 \cdot 5\end{array}$ & $\begin{array}{l}1.2 \pm 0.3 \\
2.8 \pm 2.2 \\
1.9 \pm 0.4\end{array}$ & $\begin{array}{l}15 \cdot 6 \pm 2 \cdot 1 \\
14 \cdot 2 \pm 4 \cdot 0 \\
13 \cdot 2 \pm 1 \cdot 5\end{array}$ & $\begin{array}{l}15 \cdot 1 \pm 1 \cdot 9 \\
21 \cdot 1 \pm 4 \cdot 7 \\
21 \cdot 0 \pm 5 \cdot 0\end{array}$ & $\begin{array}{l}26 \cdot 5 \pm 3 \cdot 1 \\
15 \cdot 2 \pm 4 \cdot 5 \\
17 \cdot 2 \pm 3.0\end{array}$ & $\begin{array}{l}0.6 \pm 0.5 \\
0.7 \pm 0.6 \\
1.2 \pm 0.9\end{array}$ & $\begin{array}{l}2.9 \pm 0.9 \\
3.7 \pm 0.9 \\
2.6 \pm 0.9\end{array}$ & $\begin{array}{l}9 \cdot 3 \pm 2 \cdot 0 \\
8 \cdot 6 \pm 2 \cdot 6 \\
9 \cdot 3 \pm 1 \cdot 5\end{array}$ \\
\hline $\mathbf{P}$ & $<0.05$ & $<0.01$ & $<0.05$ & & $<0.01$ & $<0.01$ & & $<0.01$ & \\
\hline $\begin{array}{l}\text { Percentage Fatty Acids in } \\
\text { Controls } \\
\text { Malabsorbers } \\
\text { Patients }\end{array}$ & $\begin{array}{l}\text { Cholesterol } \\
1.0 \pm 0.3 \\
1.7 \pm 1.1 \\
1.6 \pm 0.2\end{array}$ & $\begin{array}{l}\text { ster } \\
12.5 \pm 1.9 \\
16.4 \pm 3.4 \\
15.6 \pm 0.3\end{array}$ & $\begin{array}{l}3.2 \pm 0.7 \\
6.2 \pm 2.6 \\
5.9 \pm 0.8\end{array}$ & $\begin{array}{l}2.5 \pm 1 \cdot 3 \\
4.4 \pm 2.1 \\
3.8 \pm 0.7\end{array}$ & $\begin{array}{l}21 \cdot 6 \pm 2 \cdot 0 \\
30 \cdot 6 \pm 5 \cdot 2 \\
27 \cdot 1 \pm 2 \cdot 2\end{array}$ & $\begin{array}{l}47 \cdot 0 \pm 12 \cdot 8 \\
30 \cdot 2 \pm 7 \cdot 3 \\
36 \cdot 0 \pm 3 \cdot 1\end{array}$ & $\begin{array}{l}0.6 \pm 0.2 \\
0.7 \pm 0.4 \\
1.4 \pm 1.3\end{array}$ & $\begin{array}{l}0.7 \pm 0.4 \\
1.0 \pm 0.5 \\
0.4 \pm 0.4\end{array}$ & $\begin{array}{l}6.4 \pm 1 \cdot 7 \\
6 \cdot 3 \pm 1.4 \\
6 \cdot 6 \pm 0.9\end{array}$ \\
\hline $\mathbf{P}$ & & $<0.01$ & $<0.01$ & $<0.05$ & $<0.01$ & $<0.01$ & $<0.05$ & $<0.05$ & \\
\hline $\begin{array}{l}\text { Percentage Fatty Acids in } \\
\text { Controls } \\
\text { Malabsorbers } \\
\text { Patients }\end{array}$ & $\begin{array}{r}\text { riglyceride } \\
1.5 \pm 0.4 \\
2.5 \pm 1.0 \\
1.6 \pm 0.4\end{array}$ & $\begin{array}{l}23 \cdot 9 \pm 3 \cdot 1 \\
25 \cdot 0 \pm 4 \cdot 3 \\
27 \cdot 4 \pm 1 \cdot 9\end{array}$ & $\begin{array}{l}3.2 \pm 1.0 \\
6.0 \pm 2.5 \\
5.6 \pm 1.1\end{array}$ & $\begin{array}{l}5.1 \pm 1.6 \\
5.6 \pm 2.5 \\
5.2 \pm 0.7\end{array}$ & $\begin{array}{l}45 \cdot 7 \pm 3 \cdot 7 \\
46.9 \pm 4.9 \\
48.7 \pm 2 \cdot 2\end{array}$ & $\begin{array}{r}16.2 \pm 4.0 \\
8.8 \pm 2.7 \\
8.6 \pm 1.7\end{array}$ & $\begin{array}{l}0.9 \pm 0.4 \\
1.0 \pm 1.2 \\
0.4 \pm 0.4\end{array}$ & $\begin{array}{l}0.7 \pm 0.5 \\
0.5 \pm 0.5 \\
0\end{array}$ & $\begin{array}{l}1.3 \pm 0.6 \\
1.0 \pm 0.4 \\
1.3 \pm 0.2\end{array}$ \\
\hline $\mathbf{P}$ & $<0.01$ & & $<0.01$ & & & $<0.01$ & & & \\
\hline
\end{tabular}

Table II Fatty acid composition of lipids in whole plasma from healthy controls and from patients with or without malabsorption

${ }^{1}$ Denotes number of carbon atoms and number of double bonds in each fatty acid.

${ }^{2} \mathbf{n}=$ number of subjects.

Values represent mean \pm 1 SD. 


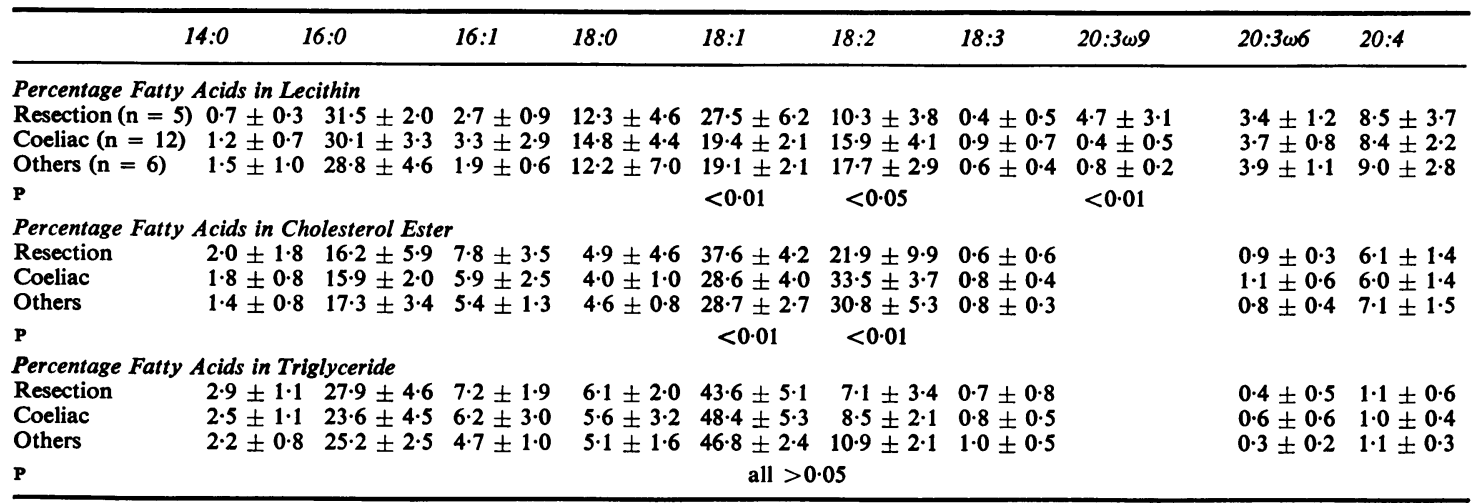

Table III Fatty acid composition of plasma lipids in patients with various types of malabsorption

FATTY ACID PATTERNS IN VARIOUS TYPES OF MALABSORPTION

The fatty acid composition of plasma lipids in patients with malabsorption secondary to intestinal resection, adult coeliac disease, or other causes is shown in table III. The resection patients were found to have significantly less linoleate and more oleate in lecithin than the other two groups of malabsorbers. Furthermore, two out of the five resection patients (nos. 4 and 6, table I) showed the presence in plasma lecithin of significant amounts (7.5 and 7.8\%) of an abnormal fatty acid, with the $R f$ of $5,8,11$

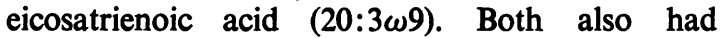
decreased amounts of arachidonate in their plasma lecithin (5.1 and 5.8\%), whereas this was normal in the other three resection patients. The linoleate content of cholesterol ester was also lower and the oleate content higher in resection patients than in the other two groups of malabsorbers, but the fatty acid pattern of their triglycerides did not differ significantly.

\section{FATTY ACID COMPOSITION OF PLASMA LIPOPROTEINS}

The fatty acid patterns of lipids in lipoproteins from healthy controls are shown in table IV. It can be seen that slight but significant differences exist between each of the lipoprotein classes. The lecithin of HDL contains less myristate, palmitoleate and oleate, and more arachidonate $(20: 4)$ than LDL and VLDL, whereas the cholesterol esters of VLDL contain more myristate, palmitate, palmitoleate, and stearate and less linoleate than low density and high density lipoprotein. In contrast, there was no difference in triglyceride composition between the three lipoprotein classes.

Comparison of the fatty acid composition of lipoproteins from patients with malabsorption

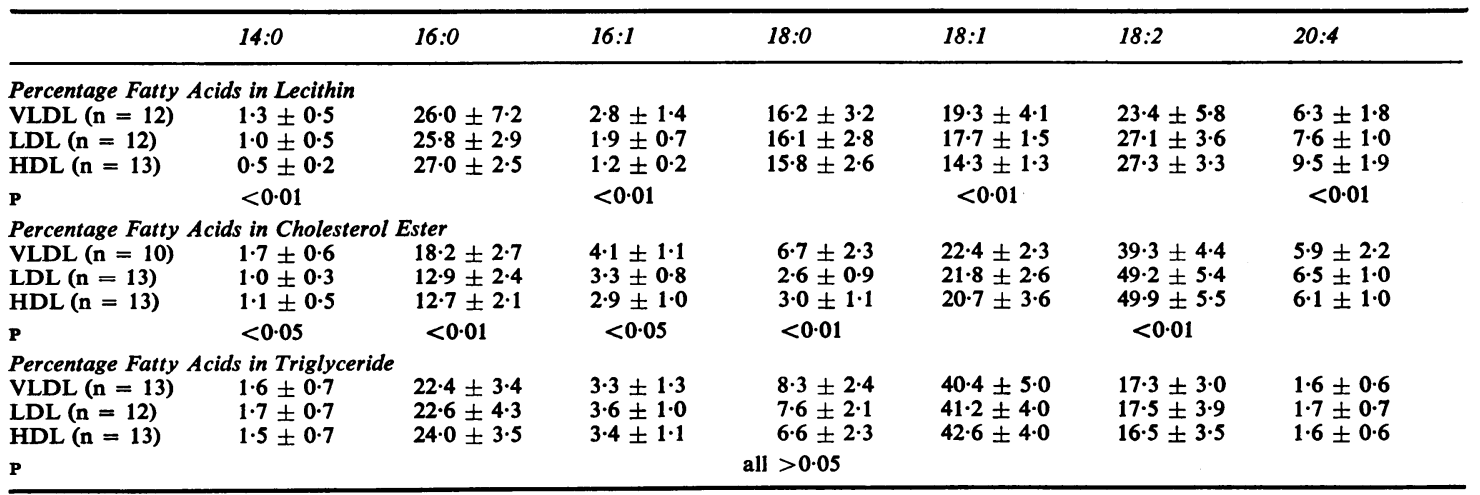

Table IV Fatty acid composition of lipoprotein lipids in plasma of healthy controls 


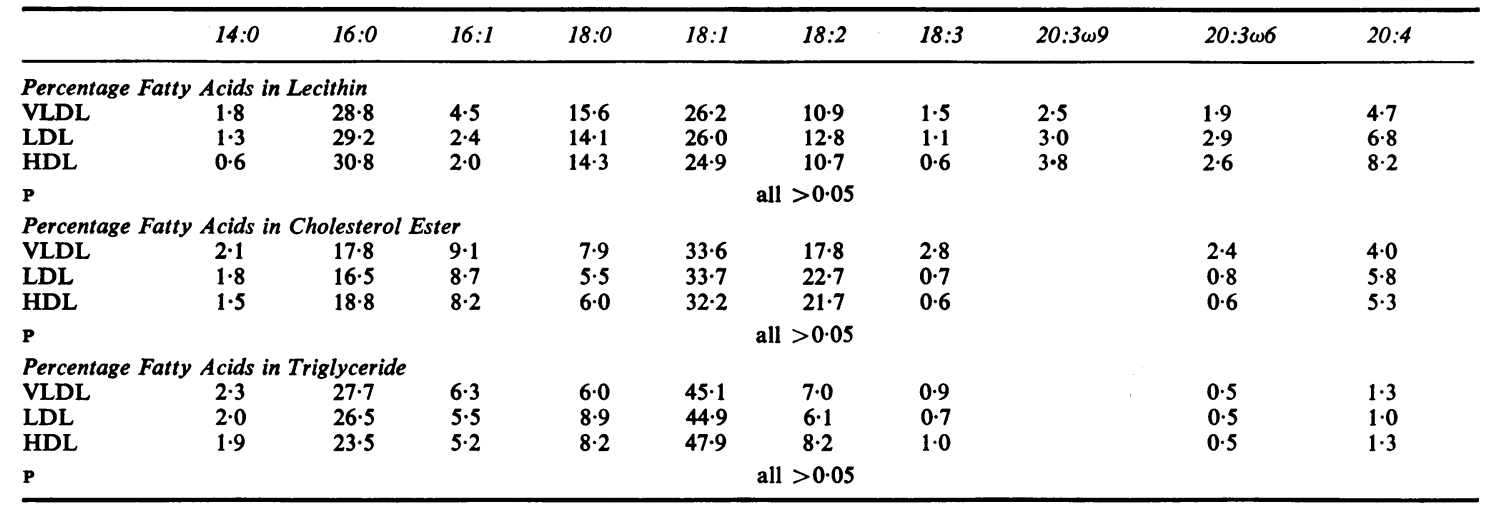

Table V Fatty acid patterns of lipoprotein lipids in five patients with intestinal resection

following intestinal resection showed that the interspecies differences noted in control subjects were no longer detectable (table V).

\section{Discussion}

The results of this study show that a marked decrease in the linoleate content of plasma lipids occurred in adult patients with malabsorption compared with healthy controls. This decrease affected the percentage composition of the fatty acids of lecithin and cholesterol ester to a more marked extent than those of triglyceride and was accompanied by reciprocal increases in the proportion of saturated and monounsaturated fatty acids. Many of these patients had reduced concentrations of cholesterol ester, triglyceride, and phospholipid in their plasma (Thompson and Miller, in press), so that there was often an absolute as well as a proportional decrease in plasma linoleate. These findings extend those previously reported in children with steatorrhoea secondary to cystic fibrosis of the pancreas (Kuo and Huang, 1965) or coeliac disease (Rey et al, 1965) and in a solitary adult with idiopathic steatorrhoea (Webb, James, and Kellock, 1960). However, the fact that similar but lesser abnormalities were observed in 'sick' controls, who did not have steatorrhoea, suggests that malabsorption of dietary linoleate was not the sole factor involved. Differences between the fatty acid composition of the hospital and healthy controls' diets and a reduced intake of fat due to anorexia undoubtedly played a major role in both groups of patients. Furthermore, it has been shown that a reduced proportion of linoleate is found in the plasma in liver disease (Caren and Corbo, 1966; Sullivan, Kelly, and Suchy, 1969), and, since non-specific hepatic dysfunction is a common accompaniment of pyrexial illnesses (Neale, Caughey,
Mollin, and Booth, 1966), this could also have been a contributory factor in the 'sick' controls.

A comparison of the different categories of malabsorption showed that changes in plasma fatty acid composition were more marked in resection patients than in those with adult coeliac disease or steatorrhoea due to other causes, such as pancreatic dysfunction. This difference was not apparently related to the severity of the malabsorption since, if anything, steatorrhoea was least marked in the resection group; nor did it correlate with the duration of illness. Unequivocal evidence of essential fatty acid deficiency, defined as the presence of significant amounts ( $>5 \%$ ) of $5,8,11$ eicosatrienoic acid in plasma lecithin (AaesJorgensen, 1961), was observed in only two patients, in both of whom there was a concomitant fall in arachidonate. In the presence of linoleic acid deficiency arachidonic acid formation is decreased and the normally inactive pathway whereby oleic acid is converted to $5,8,11$, eicosatrienoic acid is derepressed, as discussed by Ullman and Sprecher (1971). The levels of 5,8,11 eicosatrienoic acid observed in these patients, both of whom had undergone major intestinal resections, were similar to those reported in a child (Caldwell, Jonsson, and Othersen, 1972) and an adult (Collins et al, 1971) who developed clinical signs of essential fatty acid deficiency, also following extensive resections of the small intestine. However, both these patients had previously received prolonged intravenous nutrition with a fat-free source of calories, which ours had not. Another factor which can adversely influence plasma essential fatty acid levels is supplementation of the diet with medium chain triglycerides (Kuo and Huang, 1965); this may have accentuated the essential fatty acid deficiency of one of our resection patients. At the time the present 
study was performed neither of our patients showed any unequivocal clinical evidence of essential fatty acid deficiency. However, subsequently one of them developed a skin rash. This disappeared after treatment, as did the 5,8,11 eicosatrienoic acid from her plasma lecithin (Press, Kikuchi, and Thompson, 1972).

The fatty acid composition of individual lipoproteins in normal subjects has been studied on previous occasions. Lindgren and Nichols (1961) showed that the fatty acid composition of the Sf 20-10 lipoprotein fraction (VLDLand chylomicrons) contained more palmitate, stearate, and oleate and less linoleate and arachidonate than the Sf 0-20 (LDL) and HDL fractions. They also showed that the arachidonic acid content of plasma phospholipid increased with increasing lipoprotein density, being highest in high density lipoproteins. Their results were criticized by Goodman and Shiratori (1964) who found much slighter differences in fatty acid composition. Nevertheless, the latter authors' data did show that the cholesterol esters of VLDL contained a significantly higher proportion of oleate and lower proportion of linoleate than either low or high density lipoproteins. The present study confirms that these differences exist in healthy subjects although it is of interest that they were not found in patients with severe essential fatty acid depletion or deficiency. This suggests that differences between the cholesterol esters of lipoprotein classes are due to preferential incorporation of linoleate into low and high density as opposed to very low density lipoproteins. The mechanism involved might be explained if VLDL cholesterol esters could be shown to originate in the liver, as probably occurs in the rat (Gidez, Roheim, and Eder, 1967). This is in contrast to LDL and HDL cholesterol esters which are thought to be chiefly formed in the plasma. The enzyme involved, lecithin cholesterol acyl transferase (LCAT), preferentially acts on polyunsaturated fatty acids in the 2-position of lecithin rather than on saturated fatty acids in the 1-position (Glomset, 1968). Alternatively it may be that the VLDL cholesterol esters originate in the small intestine, which is known to contribute to plasma VLDL (Jones and Ockner, 1971), and which preferentially esterifies cholesterol with oleic acid (Norum and Gjone, 1967). Whichever interpretation is correct the concept that the lipids of all three lipoprotein classes have a common origin (Goodman, 1965) needs to be re-examined.

Some degree of essential fatty acid 'depletion' appears to be common in hospitalized patients, whether or not they have malabsorption. Actual deficiency is much less frequent and seems to have a special predilection for patients who develop mal- absorption secondary to intestinal resection, although it is not immediately apparent why this should be so. Studies of biliary phospholipid excretion in the Rhesus monkey do not suggest that intestinal resection would result in an increased loss of linoleate via that pathway (Dowling, Mack, and Small, 1971). It remains to be seen whether intestinal bypass, which has been used as a means of lowering serum cholesterol levels in hyperlipidaemic patients with atheroma (Buchwald, 1969), can also lead to changes in metabolism of essential fatty acids. Detection of essential fatty acid deficiency in patients at risk may sometimes be of clinical importance because the cutaneous manifestations, which include poor wound healing, and the accompanying anaemia and thrombocytopenia, can all be reversed by linoleic acid. Intravenous administration of a soya bean oil emulsion (Intralipid) appears to be particularly useful in this respect (Collins et al, 1971; Caldwell et al, 1972; Press et al, 1972).

We wish to express our thanks to Miss Janet Heath for her expert assistance and to Dr David Gompertz for his helpful advice and criticism. This study was supported in part by a grant from Unilever.

\section{References}

Aaes-Jorgensen, E. (1961). Essential fatty acids. Physiol. Rev., 41, 1-51. Alfin-Slater, R. B., and Aftergood, L. (1968). Essential fatty acids reinvestigated. Physiol. Rev., 48, 758-784.

Buchwald, H. (1969). Ileal bypass in the treatment of the hyperlipidemias. J. Atheroscler. Res., 10, 1-4.

Caldwell, M. D., Jonsson, H. T., and Othersen, H. B., Jr. (1972) Essential fatty acid deficiency in an infant receiving prolonged parenteral alimentation. J. Pediat., 81, 894-898.

Caren, R., and Corbo, L. (1966). Plasma fatty acids in pancreatic cystic fibrosis and liver disease. $J$. clin. Endocr., 26, 470-477.

Collins, F. D., Sinclair, A. J., Royle, J. P., Coats, D. A., Maynard, A. T., and Leonard, R. F. (1971). Plasma lipids in human linoleic acid deficiency. Nutr. Metab., 13, 150-167.

Dowling, R. H., Mack, E., and Small, D. M. (1971). Biliary lipid secretion and bile composition after acute and chronic interruption of the entero-hepatic circulation in the Rhesus monkey. IV. Primary biliary physiology. J. clin. Invest., 50, 1917-1926.

Folch, J., Lees, M., and Sloane-Stanley, G. H. (1957). A simple method for the isolation and purification of total lipides from animal tissues. J. biol. Chem., 266, 497-509.

Gidez, L. I., Roheim, P. S., and Eder, H. A. (1967). Turnover of cholesteryl esters of plasma lipoproteins in the rat. J. Lipid Res., 8, 7-15.

Glomset, J. A. (1968). The plasma lecithin:cholesterol acyl transferase reaction. J. Lipid Res., 9, 155-167.

Goodman, D. S. (1965). Cholesterol ester metabolism. Physiol. Rev., 45, 747-839.

Goodman, D. S., and Shiratori, T. (1964). Fatty acid composition of plasma lipoprotein fractions. J. Lipid Res., 5, 307-313.

Hansen, A. E., Wiese, H. F., Boelsche, A. N., Haggard, M. E., Adam D. J. D., and Davis, H. (1963). Role of linoleic acid in infant nutrition. Pediatrics, 31, 171-192.

Havel, R. J., Eder, H. A., and Bragdon, J. H. (1955). The distribution and chemical composition of ultracentrifugally separated lipoproteins in human serum. J. clin. Invest., 34, 1345-1353.

Jones, A. L., and Ockner, R. K. (1971). An electron microscopic study of endogenous very low density lipoprotein production in the intestine of rat and man. J. Lipid Res., 12, 580-589.

Kayden, H. J., Karmen, A., and Dumont, A. (1963). Alterations in the fatty acid composition of human lymph and serum lipoproteins by single feedings. $J$. clin. Invest., 42, 1373-1381. 
Kuo, P. T., and Huang, N. N. (1965). The effect of medium chain triglyceride upon fat absorption and plasma lipid and depot fat of children with cystic fibrosis of the pancreas. J. clin. Invest., 44, 1924-1933.

Lindgren, F. T., and Nichols, A. V. (1961). Fatty acid composition of the serum lipoproteins. Ann. N.Y. Acad. Sci., 94, 55-70.

Neale, G., Caughey, D. E., Mollin, D. L., and Booth, C. C. (1966). Effects of intrahepatic and extrahepatic infection on liver function. Brit. med. J., 1, 382-387.

Nichols, A. V. Rehnborg, C. S., Lindgren, F. T., and Wills, R. D. (1962). Effects of oil ingestion on lipoprotein fatty acids in man. J. Lipid Res., 3, 320-326.

Norum, K. R., and Gjone, E. (1967). Familial plasma lecithin: cholesterol acyltransferase deficiency. Scand.J. clin. Lab. Med., 20, 231-243.

Press, M., Kikuchi, H., and Thompson, G. R. (1972). Essential fatty acid deficiency secondary to intestinal malabsorption (Abstr.). Gut, 13, 837.

Rey, J., Frezal, J., Polonovski, J., and Lamy, M. (1965). Modifications des lipides plasmatiques dans les troubles de l'absorption intestinale chez l'enfant. Rev. franc. Etud. clin. biol., 10, 488-494. Sullivan, J. F., Kelly, M., and Suchy, N. (1969). The pattern of serum triglyceride fatty acids in Laennec's cirrhosis. Amer. J. Dig. Dis., 14, 864-869.

Thompson, G. R., and Miller, J. P. Plasma lipoprotein changes in malabsorption. Clin. Sci. (in press).

Ullman, D., and Sprecher, H. (1971). An in vitro and in vivo study of the conversion of eicosa-11,14-dienoic acid to eicosa-5,11,14trienoic acid and of the conversion of eicosa-11-enoic acid to eicosa-5,11-dienoic acid in the rat. Biochim. biophys. Acta (Amst.), 248, 186-197.

Webb, J. P. W., James, A. T., and Kellock, T. D. (1960). The effect of changes in dietary fat on the fatty acid composition of faecal lipids from subjects with normal and abnormal fat absorption. Colloques Internationaux du Centre National de la Recherche Scientifique, XCIX, Digestion, Absorption intestinale et Transport des Glycerides chez les animaux superieurs, 1-9.

\section{The August 1973 Issue}

\section{THE AUGUST 1973 ISSUE CONTAINS THE FOLLOWING PAPERS}

The cell cycle time in the flat (avillous) mucosa of the human small intestine NICHOLAS WRIGHT, ALEXANDER WATSON, ADRIAN MORLEY, DAVID APPLETON, JANET MARKS, AND ADRIAN DOUGLAS

The action of the C-terminal octapeptide of cholecystokinin and related peptides on pancreatic exocrine secretion SUMIO NAKAJIMA

Studies on the quantitation of immunoglobulin in human intestinal secretions R. R. SAMSON, D. B. L. MCCLELLAND, AND D. J. C. SHEARMAN

Inheritance and influence of histocompatibility (HL-A) antigens in adult coeliac disease P. L. STOKES, P. ASQUITH, G. K. T. HOLMES, PAULINE MACKINTOSH, AND W. T. COOKE

The metabolism of salicylazosulphapyridine in ulcerative colitis. I. The relationship between metabolites and the response to treatment in inpatients. II. The relationship between metabolites and the progress of the disease studied in outpatients K. M. DAS, M. A. EASTWOOD, J. P. A. MCMANUS, AND W. SIRCUS

The diagnosis of iron deficiency in patients with Crohn's disease J. A. CHILD, B. BROZOVIĆ, N. H. DYER, D. L. MOLLIN, AND A. M. DAWSON
A further case of chronic ulcerative enteritis B. $K$. ARMSTRONG, R. K. AMMON, L. R. FINLAY-JONES, R. A. JOSKE, AND A. B. VIVIAN

The effect of medium-chain triglyceride on ${ }^{47}$ calcium absorption in patients with primary biliary cirrhosis K. KEHAYOGLOU, ST. HADZIYANNIS, P. KOSTAMIS, AND B. MALAMOS

The effects of varying the extent of the vagotomy on the myoelectrical and motor activity of the stomach C. J. STODDARD, W. E. WATERFALL, B. H. BROWN, AND H. L. DUTHIE

An evaluation of the Hollander test by graded vagotomy in the dog S. NUNDY AND J. H. BARON

\section{Technique}

A new tube for use in the fluorescein string test: Localization of oesophageal and gastric bleeding sites with or without the use of radiography FRED E. PITTMAN

\section{Progress report}

The pathogenesis of cholera and some wider implications G. E. SLADEN

Notes and activities

Copies are still available and may be obtained from the PUBLISHING MANAGER, BRITISH MEDICAL ASSOCIATION, TAVISTOCK SQUARE, LONDON WC1H 9JR, price $87 \frac{1}{2} \mathrm{p}$ 